\title{
Cortical Pain Image or Pain-sensitivity Panel*
}

\author{
G. W. THEOBALD, $†$ M.A., M.D., M.R.C.P., F.R.C.S., F.R.C.O.G.
}

Pain is an apperceptive mental experience which can only be studied in man. It cannot be measured or even satisfactorily described except to those who have suffered like pain, and the similarity is always an assumption. The purpose of this paper is to propound the following hypothesis, which consists of two main parts: (1) that pain is meant to subserve a purely protective function and merely to cause sufficient discomfort to warn of noxious stimuli and to make the animal take appropriate action, such as to move from harm or rest a limb; and (2) that the affective or cortical component of pain, or the pain image, can be envisaged as a panel comparable with a multi-channel electromanometric recording apparatus, which allows the size of the image or the amount of deflection of the pen to be varied by turning knobs on the panel which change its sensitivity. It will be shown that pain sensitivity can be affected by (a) psychical, and (b) peripheral factors, and that it may also be modified in the spinal cord. The thesis will be supported by gynaecological experience, which gave it birth.

\section{Protective Aspect of Pain}

"Pain is the psychical adjunct of an imperative protective reflex" (Sherrington, 1940). Blindness and deafness in a wild animal are incompatible with survival in the jungle, but pain is probably of all sensations the most protective for civilized man. It is difficult, if not impossible, to preserve unimpaired vision in an anaesthetic eye, and, apart from pain, surgery would have little success in the treatment of acute abdominal conditions, most fractures would become compound, and many medical conditions would be impossible to diagnose in their early stages. Patients with syringomyelia often burn their flesh until the smell thereof warns them, but leprosy, with its millions of sufferers, provides the best example of the protective value of sensation. Tissue destruction in these patients is not directly due to the disease, but to trauma and self-damage because of loss of sensation. They grip instruments ferociously, and so damage their hands, and this provides one of the finest examples of the correlation between tactile and pain sensation. "The leprosy patient seems really to regard his hands and feet as dead. He cannot feel them, and he regards them, I think, much as he would regard a chisel or a pair of pliers" (Brand, 1964). Rats and mice tend to eat their own limbs if they are made anaesthetic.

\section{Pain Image}

The affective or cortical component of pain may be regarded as the pain image which every individual builds for himself (Theobald, 1949a, 1949b), just as a child learns to build his own image of space and environment (Head and Holmes, 1911). But whereas the child learns to build his image of space by throwing out his antennae into it, he builds his image of pain largely from sensations other than those of pain. Imagination, excitement, and fear, fed by an environment which includes the cinema, television, and books, are some of the bricks used to

\footnotetext{
* Being the substance of lectures delivered when Visiting Professor in Obstetrics and Gynaecology, Western Reserve University, Cleveland, Ohio, and at Kingston University, Ontario, and at Lund University, Sweden.

† From the Obstetric Unit, University College Hospital, London.
}

build this image, and the mortar which holds them together comprises aspirin, codeine, and other drugs from slot-machines and the black market.

It is suggested that this image may be regarded as a panel on which there are several knobs which control the sensitivity of the different parts of the body. The built-in sensitivity range is established over the years and is largely fixed by hereditary and environmental factors, and this range is difficult to alter. although it declines with age. Within this compass sensation may be altered by changes in bodily health and mental equilibrium, by alcohol, by drugs, and in many diverse ways. Further, different channels, which subserve discrete parts of the body, may vary widely in sensitivity.

\section{General Considerations}

The body is wrapped around with a protective covering of skin, and part, but only part, of this protection lies in the fact that it contains nerve endings which collect for transmission stimuli culled from the enviroment. A child born blind, deaf, and dumb, unless he receives especial awakening and instruction, is liable to sleep his life away and to remain relatively insensitive to stimuli which cause pain in the normal individual. Development of the mind, therefore, is dependent on stimuli from the outer environment which reach the skin, or modified skin (eyes and ears), and the resultant impulses travel along nerve pathways to specific parts of the brain.

Vision may afford pleasure or warn of danger, whereas noxious stimuli threaten danger not only to the portion of skin affected but possibly to the whole body. Noxious stimuli can arise as well in the deeper structures of the body, including the viscera, as in the skin.

\section{Nerve Endings}

Impulses from sensory stimuli picked up by nerve endings travel in special pathways to, and in, the spinal cord, and thus reach specific parts of the brain. It is their destination which determines their message, for the exact nature and site of any particular experience depend entirely on which group of brain cells is activated (Adrian, 1947). A mere decade ago it was thought that free or naked terminal nerve fibres could only subserve pain sensation and that other modalities necessitated specialized end-organs. To-day no such rigid demarcation is accepted so far as the skin is concerned, and some think that the same endings may subserve different sensations (Keele and Armstrong, 1964). The difficulty in deciding this point lies in the extreme complexity of the arrangement of cutaneous nerves, and it is doubtful if the stimulation of a single nerve fibre would result in any sensation (Sinclair, 1955). Skin nerve endings are insulated, and if this insulation becomes defective efferent impulses could affect afferent nerve endings, either directly or by the metabolites they release.

Impulses arising from nerve endings, whether in the skin or in the deeper structures of the body, pass to the spinal cord and thence to the brain at a speed largely determined by the size of the cross-section of the nerve in which they travel. They move as the result of the combined operation of electrolyte movement, selective membrane permeabilities, and chemical 
transmitters, and there is no component of either pleasure or pain in them. There is therefore no such thing as a pain-nerve ending, a pain nerve, or a pain impulse, for the impulses which result from a kiss, a thrashing, or the smell of a rose are in most respects identical and are but measurable electrical currents. The determining factor is the destination, and the electrical currents are decoded differently by different cells in different parts of the brain, and are furthermore transmuted into the sensations we feel ; we know not how and possibly never shall. It may here be noted that non-specific mechanisms in the central core of the brain stem may modify nerve impulses travelling in all directions and at all levels in the central nervous system (Magoun, 1963).

Nerve impulses mediating the sensation of pain travel in the spinothalamic tract and reach the pain-apperception centre in the thalamus. Thence projections are carried to the cortex and impulses pass in both directions which can both increase and decrease pain sensibility. Then, too, the concept of competition for nerve channels and terminals must operate, so that great excitement enjoining maximum attention temporarily precludes impulses caused by noxious stimuli from achieving conscious recognition (Barraclough and Cross, 1963). Seeing that visceral stimulation can evoke potentials in the cerebral cortex (Downman, 1951 ; Abrahams, Langworth, and Theobald, 1964), it may well be that some nerve fibres subserving the sensation of pain may proceed direct to the cortex.

\section{Built-in Sensitivity Range for Pain}

Gently nurtured women and "sensitive" individuals both enjoy pleasure and feel pain more intensely than do ordinary mortals. On the other hand, those brought up hard suffer but little pain. Officers and men of Napoleon's Grand Army sat on a drum-head and had their limbs amputated without evincing much evidence of suffering. It is even recorded that one officer, after having had an arm and a leg amputated, got on to a horse and took a despatch across Europe. By the time he returned both wounds had healed. The great-granddaughters of those men carry codeine tablets in their handbags in case of dysmenorrhoea or a headache, while the great-grandsons demand an anaesthetic for tooth extraction. Leriche (1939) reported that in Russian operating-theatres during the first world war fingers and hands were amputated without any anaesthetic, and that he was forced to conclude that those Cossacks felt no pain. Pain sensitivity, therefore, is clearly not a matter of the century in which men lived but more a matter of how they live.

\section{Psychical Component of Pain Sensitivity}

The concept of a pain-sensitivity panel presupposes that psychical factors are largely concerned in its development. The very thought of a surgical incision, which amounts to little more than a cut while shaving, causes fear unless an anaesthetic is promised. Alone at night in the dark, pain hardly noticed by day may become intolerable. Conversely, excitement, whether during a game or in battle, may make a man oblivious to all pain. Functional disease may be associated with complete motor and sensory loss affecting one or more limbs, and although there is no organic lesion the subject may go down to the grave uncured. Mental concentration may prevent a man from feeling either hunger or pain, and loud music combined with "white noise" (supposed to resemble the sound of a waterfall) may prevent pain sensation during dental operations (Gardner, Licklider, and Weiss, 1960). Concentration on sensory-motor tasks while deliberately ignoring sensory distractions often affords relief to sufferers from phantom-limb pain (Morgenstern, 1964).

Prefrontal leucotomy may either completely relieve the most severe and intractable pain or abolish the distress associated with it. It is supposed that when the fibres are cut between thalamus and cortex the basal pain persists but the cortical component, with its unpleasantness, is removed.

Hypnosis affords perhaps the most convincing evidence of the part played by psychical factors both in relieving and in causing pain. More than a century ago a large series of abdominal operations were done under hypnotic suggestion alone, and minor operations under its sole influence have recently been demonstrated on the television screen. Pain may prevent wounds and long-lasting ulcers from healing, and in such cases hypnotic suggestion has been used to achieve rapid recovery (Bramwell, 1896). Conversely, pain can be caused by suggestion. If the skin be touched with the cap of a fountain-pen and the suggestion made that it is red-hot, the subject will groan and writhe in agony, and a weal may form. If an area of skin on the forearm be delineated with a pencil and the suggestion made that it will be very sore after he awakens, that specific area of skin will be sore even if it be innervated by two separate nerves, and, further, be infiltrated with a local anaesthetic (Theobald, 1949b). Suggestion that the top of the fountain-pen is hot and that crushing the skin with an artery forceps will be painless can be carried out on two separate areas of skin on the same subject at one session. The expression on the subject's face when both pieces of plaster are removed is almost as surprising as the event itself, for the artery forceps causes marked trauma, but the injured skin is not tender to touch.

\section{Pain Sensation Modified by Peripheral Stimuli}

Stonemasons, gardeners, bricklayers, carpenters, and miners frequently damage their hands and become relatively insensitive to cuts and bruises which would bother ordinary folk. Theatre sisters used to plunge their hands into the boiling sterilizer to remove an instrument, and Indian Fakirs walk on red-hot coals with impunity. It seems that constant small traumata raise the threshold to pain of the nervous arcs concerned. A similar result can apparently be achieved by the direct opposite treatment. Dogs protected and isolated from birth seem to be unable to feel pain like other dogs, and it is concluded that " early perceptual experience determines in part at least ... the actual capacity to perceive pain normally" (Melzack and Scott, 1957). On the other hand, the cervix uteri may become so sensitive that the woman cannot tolerate a single-toothed vulsellum on its anterior lip, and even lactic acid introduced into the cervical canal causes pain.

Causalgia is a classical example of pain sensitivity affecting a small area of the body being markedly increased as the result of injury to a peripheral nerve. It has been claimed that this intractable pain, which may result in death, can be instantly cured by anaesthetizing the sympathetic ganglion immediately proximal to the lesion (Leriche, 1939).

The Hungarian School, led by Jancsó, have claimed to be able to desensitize animals to all noxious chemical stimuli by injecting capsaicin, a derivative of capsicum. Animals so treated appear to be unaffected by ammonia fumes or by chemicals distilled into the eye, but remain sensitive to noxious electrical and mechanical stimuli (Jancsó, 1958 ; Jancsó and Jancsó-Gábor, 1959). It might be mentioned in parenthesis that neuro-lept analgesia suggests the possibility of abolishing pain without affecting consciousness (de Castro and Mundeleer, 1959 ; Ingvar and Nilsson, 1961). In due course it may prove possible to render nerve endings insensitive to all noxious stimuli, and the centre itself insensitive to pain. The latter end can already be achieved through self-hypnosis and by leucotomy. The leper may in time rise up in judgment against us.

\section{Pain Sensitivity Modified by Spinal-cord Mechanism}

It is agreed that pain sensitivity is mediated by nerve fibres travelling in the spinothalamic tracts. Whether or not im- 
pulses reach consciousness is determined by synapse resistance, competition for pathways, and by non-specific mechanisms in the central core of the brain stem, to which reference has already been made (Magoun, 1963).

A patient had a vascular episode with consequent damage limited to the spinothalamic tract at the level of the sixth thoracic vertebra on the left side. The effects occurred fairly suddenly and he first noticed numbness of his feet and inability to feel the stool while defaecating. He was anaesthetic over the whole of the right side of the body below the nipple line. Temperature sensation was lost but there was no detectable loss of power. Sensation to touch and pin-prick came back slowly and patchily and was associated with both paraesthesia and hyperaesthesia. Temperature appreciation was delayed for several months, and for a time cold water caused a sensation of "electric shocks" and not of cold. For many months the leg, and in particular the knee, felt uncomfortably warm, although he felt no sensation of warmth when hot water was poured over it. The burning sensation was clearly not mediated by nerve endings.

\section{Clinical Aspects of Pain}

Pain may be closely related to previous events, such as eating (duodenal ulcer) and exercise (intermittent claudication). It can sometimes be described in such terms as burning, cutting, stabbing, and boring. Attempts have been made to distinguish between superficial and deep pain, which includes that arising in the joints and in the viscera, but it may well be that " deep pain" results from the stimulation of both somatic and autonomic nerve endings. This is one of the reasons why the term "psychosomatic" is unfortunate. Perhaps the most significant single method of describing pain is by plotting the time-intensity curve suggested by Lewis (1942) (see Chart). This indicates the very rapid onset and intensity of the pain associated with colic. It does not as a rule disappear so cleanly as shown in the graph, and is moreover often associated with intense anxiety and foreboding. The pain of labour is of relatively low intensity and of slower onset, and ends abruptly. The low-grade constant nagging pain that persists for hours and even days is the type that makes dysmenorrhoea intolerable.

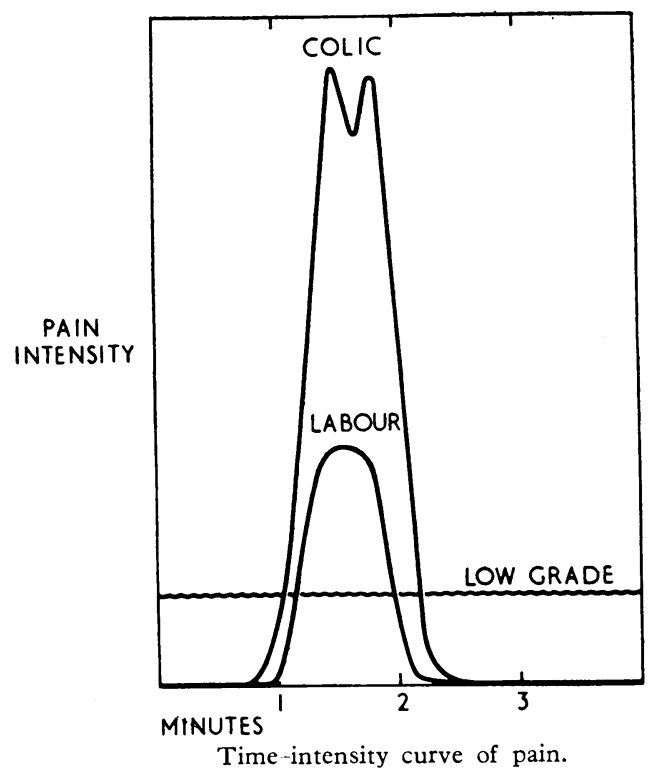

Gynaecological Evidence

A rich plexus of cholinergic nerve fibres is seen in the cervix and isthmus of the human uterus, whereas in the rest of the organ the nerve fibres are sparse and do not take the stain for cholinesterase (Coupland, 1960, 1964). The rabbit uterus contains mechano-receptors (Ferguson, 1941 ; Bower, 1959), and in the cat, potentials can be evoked both in the hypothalamus and in the cortex by electrical stimulation of the uterus (Abrahams, et al., 1964).

Stimulation of the cervix with the silver stick $\left(\mathrm{AgNO}_{3}\right)$ may cause: (1) A profound fall of blood-pressure from $120 / 80$ to $70 / 30 \mathrm{~mm}$. $\mathrm{Hg}$, and this is indubitably associated with capillary pooling-conversely, the application of the forceps or the vacuum extractor may cause a slight rise in the bloodpressure ; (2) Acute dilatation of the pupils ; (3) A cold sweat ; (4) Nausea and vomiting; (5) Antidiuresis ; (6) Severe pain.

Events 1 to 5 may precede the onset of pain, and it must be supposed that nerve pathways from the cervix reach different parts of the brain to elicit varying responses (Theobald, 1951, 1955).

\section{Uterine Pain and its Relief}

Uterine pain consists of two components, a true uterine pain, the impulses from which are "summated" with those arising in the cutaneous area of reference, and both of these components can be separately measured (Bryant, Menzies, and Theobald, 1964). Referred pain cannot be attributed to antidromic impulses or to metabolites they may liberate into the skin, for shoulder pain is caused by stimulating the phrenic nerve after the supraclavicular cutaneous nerves have been ablated by block dissection (Doran and Hall Ratcliffe, 1954). It is improbable that reference or "summation" occurs in the spinal cord, for this would spell anarchy in the central nervous system. It has been suggested that impulses from the viscus and the cutaneous area of reference ultimately reach the same group of cells in the cortex (Theobald, $1941 ; 1949 b$ ). Uterine pain up to a certain intensity can be relieved by anaesthetizing the cutaneous area of reference, and beyond that intensity the pain recurs and is referred to the same area of skin, although it is anaesthetic.

Dysmenorrhoea occurs infrequently with the first period, and this is presumptive evidence that imperfect uterine development is not its cause. Some girls are free from pain except when they are tired or run down, for whatsoever reason. It is a catching condition whether from mother or sister or from other girls at school. Approximately $60 \%$ of those who suffer such pain can be cured by exercises and of ten even by persuading them to walk to work instead of riding in a bus or car. Falling in love may cure the condition and unhappy marriage may precipitate it.

The pangs of childbirth are proverbial. They recur at frequent intervals, and between them the woman is free from pain (see Chart). She may therefore spend labour anticipating the next pain or in gratitude for freedom from all pain in the intervals between them. The total duration of pain during the whole course of labour is occasionally less than 20 minutes, commonly under 90 minutes, and should rarely be allowed to exceed 150 minutes. She thus has freedom from pain for more than four times as long as she suffers. It is easy to make her suffering worse by inculcating fear, leaving her alone (particularly in the dark), by unfriendliness, and by allowing labour to be unduly long so that dehydration occurs. It is equally easy to ameliorate pain by diverting the woman's attention from it, by never leaving her alone, and by preventing her from hearing the screams of uncontrolled patients. Some primigravidae feel no pain at all during the whole course of labour, and its successful management depends more on positive assurance than on negative analgesics.

\section{Uterine Pathology}

The pain so far discussed occurs in healthy women. One of the first signs of uterine disease is that movement of the cervix 
becomes painful. There are six possible movements, each of which may cause pain referred to a different site. Such pain may be associated with an apparently healthy cervix, whereas a grossly infected one may be unaccompanied by pelvic pain. Should a sinus persist after total hysterectomy, stimulation of it through the vagina, whether by chemical or electrical means, may cause pain indistinguishable from uterine pain, and this probably argues against the specificity of nervous pathways to the uterus.

\section{Dyspareunia}

If movement of the cervix with the finger causes pain, then clearly movement of it with any other object will likewise cause pain, particularly if the woman does not want intercourse. Vaginismus is the only pathological condition affecting the female pelvic organs which cannot be cured by local therapy. It is a psychical disturbance which often responds to amateur psychotherapy.

Pain does not usually, if ever, arise in the ovary. It may be exquisitely sensitive on bimanual examination, because it is palpated through more than a dozen different structures, in some of which the pain could arise. Should it prove possible to move the offending ovary directly over the sacrum it will be found possible to squeeze it hard against the bone without causing pain. Further, if the abdomen be opened under local anaesthesia the ovary can be grasped with ovum forceps, and physiological saline solution can be injected into it without causing pain.

\section{Conclusions}

It is perhaps not widely recognized that the gynaecologist is the only clinician in a position to study pain recurring in a healthy organ in a healthy individual, and moreover to provoke pain indistinguishable from that which occurs normally by means of chemical, physical, or electrical stimuli. Pain is one and indivisible into somatic and autonomic components, for it is now recognized that the autonomic inflow into the brain is possibly of the same order as that of somatic nerves (Mitchell, 1953). Pain was not meant to be painful, for its cortical adjunct is fashioned out of fantasy by fear. It remains a matter of conjecture whether it is possible for an individual with an artistic temperament to develop appreciation of any form of art to its highest intensity without at the same time increasing pain perception. The thesis which has been presented was born of gynaecological experience, and the facts concerning uterine pain support the concept of an individual pain image and a pain-sensitivity panel.

The profound part played by psychical factors in fashioning the pain image must not be allowed to obscure the part played by peripheral nerves and by cord mechanisms, for the psyche is largely built on impulses from the skin. It may well be that at great cost much gynaecological pain could be relieved by psychotherapy, but the fact remains that nearly all such pain, when surgery is not imperative, can be satisfactorily dealt with by one of two procedures: (1) overstimulating the nervous arcs involved, and (2) blocking these arcs for a while with a local anaesthetic. The underlying assumption is that after either procedure the nervous arcs resume normal activities and the impulses they carry cease to reach pain consciousness.

The pain-sensitivity panel offers a rational explanation of the obvious variation in pain sensibility from individual to individual and in the same individual at different times; for increased sensitivity in one organ or limb; and for the success of such varying treatments as psychotherapy, hypnosis, Christian Science, a visit to Lourdes, manipulative surgery, exploratory laparotomy, and health exercises. It could also solve some of the problems which have troubled theologians and philosophers, for, if pain be essential and protective, excessive painful pain is of man's own making and cannot be attributed to his Creator.

\section{REFERENCES}

Abrahams, V. C., Langworth, E. P., and Theobald, G. W. (1964). Nature (Lond.), 203, 654.

Adrian, E. D. (1947). The Physical Background of Perception. Clarendon Press, Oxford.

Barraclough, C. A., and Cross, B. A. (1963). F. Endocr., 26, 339.

Bower, E. A. (1959). 7. Physiol. (Lond.), 148, 2P.

Bramwell, J. M. (1896). Brain, 19, 459.

Brand, P. W. (1964). In the Service of Medicine, April, No. 37, 1.

Brit. med. F., 1964, 2, 5. (See Gardner et al., 1960, and Morgenstern, Bryant, G. H., Menzies, D. N., and Theobald, G. W. (1964). F. Physiol.
(Lond.), 172, 18P.

de Castro, G., and Mundeleer, P. (1959). Acta chir. belg., 58, 689.

Coupland, R. E. (1960). 7. Anat., 94, 289.

- (1964). Personal communication.

Doran, F. S. A., and Hall Ratcliffe, A. (1954). Brain, 77, 427.

Downman, C. B. B. (1951). f. Physiol. (Lond.), 113, 434.

Ferguson, J. K. W. (1941). Surg. Gynec. Obstet., 73, 359.

Gardner, W. J., Licklider, J. C. R., and Weiss, A. Z. (1960). Science, 132, 32. Quoted by Brit. med. F., 1964.

Head, H., and Holmes, G. (1911). Brain, 34, 102.

Ingvar, D., and Nilsson, E. (1961). Acta anaesth. scand., 5, 85.

Jancsó, N. (1958). Acta physiol. Acad. Sci. hung., Suppl., 12, 15. Quoted by Keele and Armstrong (1964).

and Jancsó-Gábor, A. (1959). Arch. exp. Path. Pharmak., 236, 142. Quoted by Keele and Armstrong (1964). Keele, C. A., and Armstrong, D. (1964). Substances Producing Pain
and Itch, p. 19. Arnold, London.

Leriche, R. (1939). The Surgery of Pain. London.

Lewis, T. (1942). Pain. Macmillan, New York.

Magoun, H. W. (1963). The Waking Brain, 2nd ed. Thomas, Spring-
field, Ill. Melzack, R., and Scott, T. H. (1957). F. comp. physiol. Psychol., 50,
155.

Mitchell, G. A. G. (1953). Anatomy of the Autonomic Nervous System. Livingstone, Edinburgh and London.

Morgenstern, F. S. (1964). F. Neurol. Neurosurg. Psychiat., 27, 58. Quoted by Brit. med. $\dot{f}$. (1964).

Sherrington, C. S. (1940). Man on His Nature. Cambridge Univ. Press. Sinclair, D. C. (1955). Brain, 78, 584.

Theobald, G. W. (1941). Referred Pain: A New Hypothesis. Times of Ceylon, Colombo.

(1949a). 7. Obstet. Gynaec. Brit. Emp., 56, 447.

(1949b). Lancet, 2, 41, 94.

(1951). 7. Obstet. Gynaec. Brit. Emp., 58, 733.

(1955). In Modern Trends in Obstetrics and Gynaecology, 2nd series, edited by K. Bowes, p. 129. Butterworth, London. 